\title{
Fresh Fruits and Vegetables "Last Mile" Home Delivery in China Current Situation Research
}

\author{
Xuewen Zhang, Haifang Zhang \\ School of Logistics, Beijing Wuzi University, Beijing, China \\ Email: 15202284246@163.com
}

Received 12 June 2016; accepted 22 July 2016; published 25 July 2016

Copyright (C) 2016 by authors and Scientific Research Publishing Inc. This work is licensed under the Creative Commons Attribution International License (CC BY). http://creativecommons.org/licenses/by/4.0/

c) (i) Open Access

\begin{abstract}
2012 was named as "the first year of Fresh Electronic Commerce" in China. Then the Electronic Commerce of fresh and fresh home delivery obtained rapid development. Although the development speed of fresh home delivery is fast, it still could not meet the demand of Fresh Electronic Commerce. The aim of this paper is to analyze the current situation of development of "the last mile" of Chinese fresh delivery and put forward some suggestions can be adopted for fresh delivery terminal development.
\end{abstract}

\section{Keywords}

Fresh Electronic Commerce, Fresh Fruits and Vegetables, Home Delivery, "The Last Mile”

\section{Introduction of Home Delivery with Fruits and Vegetables}

As the social economy continues growing, the income of residents is increasing and the eating habits of Chinese residents are changing. Traditional agricultural foods in the consumption gradually decline, which is replaced by fresh fruits and vegetables. At the same time, along with the city fast rhythm life, bad weather and other factors, an increasing number of people choose to buy fresh fruit and vegetables by internet. Therefore, the delivery of fresh fruits and vegetables of all types of electronic business platform meets a very well period. Through the investigation and analysis on all over the world fruit and vegetable delivery service development, it is conducive to promote the development of China's fresh fruit and vegetable delivery service, as well as to improve the quality of residents' lives. 


\subsection{Characteristics of Fresh Agricultural Products}

\section{1) Corruption}

Fresh fruits and vegetables have very high proportion of water, most of $65 \%$ to $96 \%$, even was picked still in the metabolism. Even if it is storage in a place after picked, it will be wither in a period. According to statistics, at present Chinese fruit loss from decay rate in $25 \%-30 \%$, rotten vegetables loss rate in $20 \%-25 \%$, the loss of aquatic products rate around $15 \%$, and in Europe, the United States, Japan and other developed countries on agricultural products average loss rate is only $1.7 \%-5 \%$ [1].

2) Multispecies

There are many kinds of fruits and vegetables, even the same species, there are many varieties. Different types of fruits and vegetables procurement time and methods are different. This phenomenon resulted in the unique characteristics of each fruit and vegetable, so during picking, transporting each kind of fruits and vegetables needed to design a unique program increased the difficulty of the operation of fruits and vegetables.

3) Regional characteristics

The growth of fruits and vegetables depend on the environment highly, although there are a lot of vegetables to implement greenhouse cultivation, some fruits and vegetables are still not suitable for this kind of planting method. Moreover, China covers a large territory, all fruits and vegetables have to rely on the transport to complete transaction. The expense of transport costs, obviously, great. According to statistics, the total cost of fruits and vegetables in the developed countries accounted for about $10 \%$ of the total cost, while the current cost of fruits and vegetables in China accounted for more than $50 \%$ of the cost [2]. Thus, the logistics cost of cross regional transport in China's fruits and vegetables contain a large share.

\subsection{Overview of China and International Development of Fruit and Vegetable Home Delivery}

\subsubsection{The Development of Foreign Fruit and Vegetable Home Delivery}

The fresh agricultural products purchase through the Internet, and delivery has been very popular in the United States, Japan, Holland and other developed countries. Consumers on the Internet buy fruits and vegetables what they want, choose the delivery time, place, then at an appointed time they can receive fresh, healthy fruits and vegetables.

In the United States, many enterprises have developed very good fruit and vegetable delivery. Such as the main to the development of B2C mode of the Amazon from the beginning of 2007, one after another in Seattle, Los Angeles, San Francisco and New York City began with named "Amazon fresh" fresh delivery service, including outside the distribution and the distribution of two forms. The former will be fresh food placed in the insulation box, then put besides the customer's door, the latter is required to wait at home for consumers to receive [3]. Local Harvest $\mathrm{O} 2 \mathrm{O}$ as the representative of the Local fresh electricity business platform. Harvest Local adhere to the concept of "eating in the local, eating in the season". Local sales of agricultural products in the local production, consumers can easily buy local agricultural products through the map, the local logistics and distribution can easily solve the fresh electricity supplier industry insurmountable logistics gap. Farm according to consumer demand, planting different agricultural products, offers a rich variety of food, no longer need to transport from the field to introduce, reduce logistics costs, and enhance the transparency of food production and consumption, and convenient degree and trust [4].

\subsubsection{The Development of China Fruit and Vegetable Home Delivery}

Compared with developed countries, Chinese fresh electronic commerce starts later. The year of 2012 e-commerce industry has been hailed as the first year of fresh electricity supplier, it really means that Chinese fresh e-commerce began as a rapid development, a large number of electronic business enterprises to join the fresh field. Part fresh e-commerce enterprises developed rapidly, with third party courier companies to establish the SFbest, relying on large online shopping platform to expand miao TMALL, specializes in the food network marketing companies a vertically extending Tootoo community, Youguo net.

The emergence of these enterprises, that is just a preliminary exploration of China fresh fruits and vegetables home delivery service, although part of the business about home delivery is good, there are still a lot of problems restricting the development of fruit and vegetable delivery service. First, fruit and vegetable circulation long chain hindered the shorter life cycle of fruit and vegetable delivery service development, the fruits and 
vegetables in transit is likely to deteriorate; secondly, the high expense of logistics cost, making a lot of enterprises into a Isolated stalemate.: seeing fruit and vegetable home delivery service is a very good market, but after adding either successive loss or declared bankrupt. Though Foreign fresh fruits and other agricultural products e-commerce development process, Chinese fresh fruit and vegetable home delivery service also need $\mathrm{r}$ a long accumulation, consumers from shopping tide model into the daily shopping patterns is an essential process. And China has a large population, the market size about fresh agricultural products online shopping is expected reach 400 billion in 2020 [5]. It is clear that fresh agricultural products will become a net purchase selling products in the electronic business platform.

\section{The Current Situation of the Development of Fruit and Vegetable Home Delivery in China}

\subsection{Fresh Electricity Supplier Development Model}

Entrepreneurs have found that fresh fruit and vegetable delivery service has great opportunity for development. They invested a lot of money promoted the fresh business model blowout type development. Nowadays fresh business operating mode, mainly grouped into the following categories: "own cultivated fields + home delivery" mode, "purchase + home delivery" mode, relying on sales of electronic business platform model, the expansion of traditional supermarkets to the e-commerce model.

1) "Own cultivated fields + home delivery" mode

"Own cultivated fields + home delivery" mode (as shown in Figure 1) aim at allow consumers to eat safe, rest assured organic fruits and vegetables. They almost cover the whole process of product, from product, sale, to home delivery "one-stop" services. The enterprise will select some of farm in the country to create a good environment, as organic agricultural production base. In planting, it will do the whole tracking, monitoring. Then in large cities like Shanghai, Beijing, in the way of membership choice high income families as their members, every fixed period send the organic fruit and vegetables which them need to the member's home.

Tony's Farm, is a famous organic vegetable production enterprise in Shanghai, China and is using this model, providing fresh organic fruits and vegetables for the customers. The company is one of the largest organic vegetable cultivation and sale of fresh business enterprise, Its target is to create the first brand of urban organic agriculture in China, to the consumer provide a safe, natural and healthy organic vegetables, advocate low carbon, green and environmental protection philosophy of life [6]. Tony's Farm to customer base located in Beijing, Shanghai, and from the distribution in Heilongjiang, Beijing, Shanghai, Zhejiang, Sichuan, Yunnan, Fujian, Hainan, Ningxia in different latitudes, with the temperature of the production base to rely on through organic

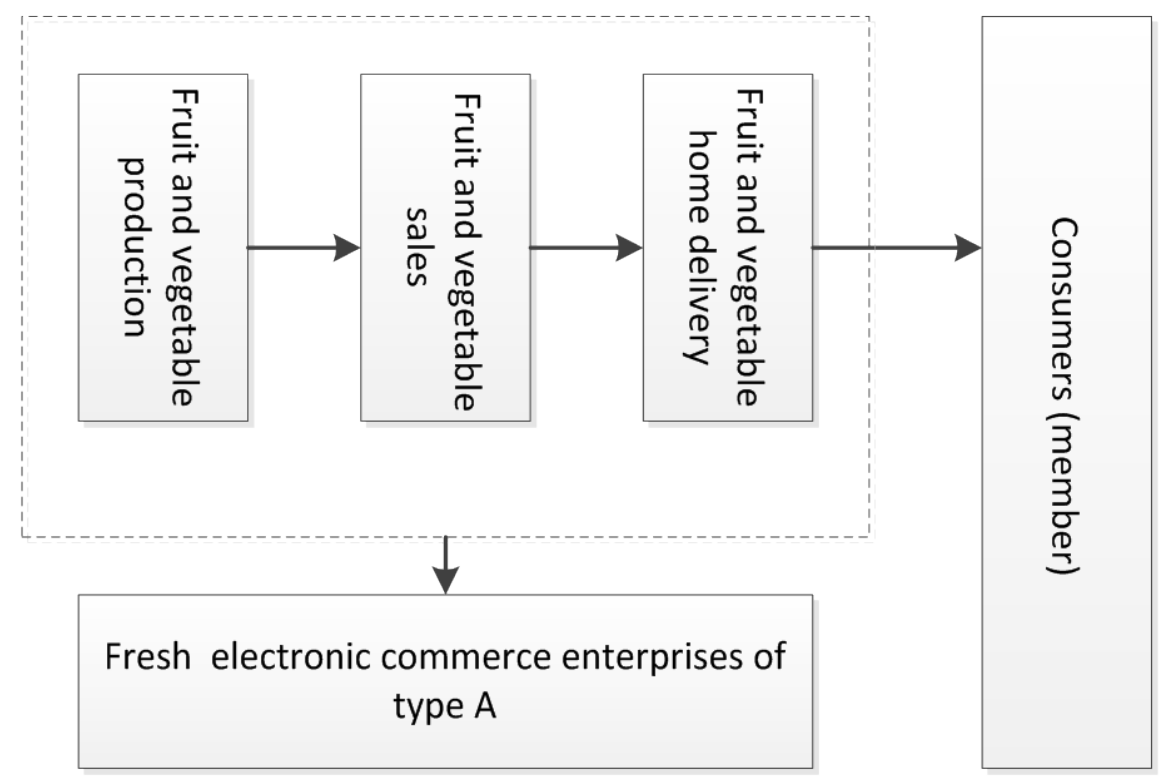

Figure 1. “Own cultivated fields + home delivery” mode operating diagram. 
farming and soil improvement, as consumers provided for many varieties of vegetables and with local characteristics of agricultural and sideline products, and through its own sales network, direct delivery to the hands of consumers, to ensure that the member of Shanghai and Beijing can eat fresh, healthy, rich variety of organic vegetables. And, in this way the sales of vegetables' traceability is extremely strong, once the problem be found, in a timely manner to identify the root causes of problems. However, the price of this model is ten times as much as the average price of vegetables, the average incomers simply do not have the ability by these vegetable as a daily consumption.

2) "Purchase + home delivery" mode

"Purchase + home delivery" mode (as shown in Figure 2) is the enterprises as a connecting link between consumers and suppliers in establishing business platform based on to the ends of the extension, and purchase by themselves to ensure the quality of fruits and vegetables. Find members in their own network platform and use their own advantages of direct distribution, to ensure the controllability of the distribution process. This mode is similar to the first mode, the difference is that this model's fresh products are through procurement, saving cost than the first model. In general, large courier companies, if they want to develop fresh electricity suppliers. They will choose this model.

There are many companies use this mode, for example, The SFbest which is SF subsidiary, Womai Net which a subsidiary of COFCO. This model has played their own strengths, it's also a good part transfer their own flawed businesses to other enterprises, then format a good supply chain system, and avoiding the high cost.

3) Relying on sales of electronic business platform model

The model (as shown in Figure 3) is mainly rely on large network platform, fresh electricity suppliers in the platform to release sales information, consumers through the platform to choose their own needs of fresh fruits and vegetables, and then distribute by the courier company. At the same time, the electricity business enterprise will establish its own official website, through the site can also sell some fresh fruits and vegetables. Most of the B2C (Business-to-Customer) fresh electricity business enterprises select this mode.

In life, there are many enterprises, such as the 1st shop, fresh channel of Jingdong and miao MALL, using this model. Consumers buy fruits and vegetables, the supply of the nearest Distribution Center for the customer distribution. At the same time, a large platform, more customers can also attract some of the companies have a certain influence on the platform to open flagship store sales. For example, Fruitday open the fruit and vegetable flagship store on the fresh channel of Jingdong. However, a wide range of distribution for this platform also brought some drawbacks. As the author checked the vegetables sales on these platforms, distribution process, just add a layer of plastic wrap on sales. Although this save the cost, consumers who far away center received the leafy vegetables may has been rancid.

4) The expansion of traditional supermarkets to the e-commerce model

Electronic business platform (as shown in Figure 4) caused an extremely big blow for the traditional supermarket sales model. Many traditional supermarkets are trying to combine the traditional mode and electricity

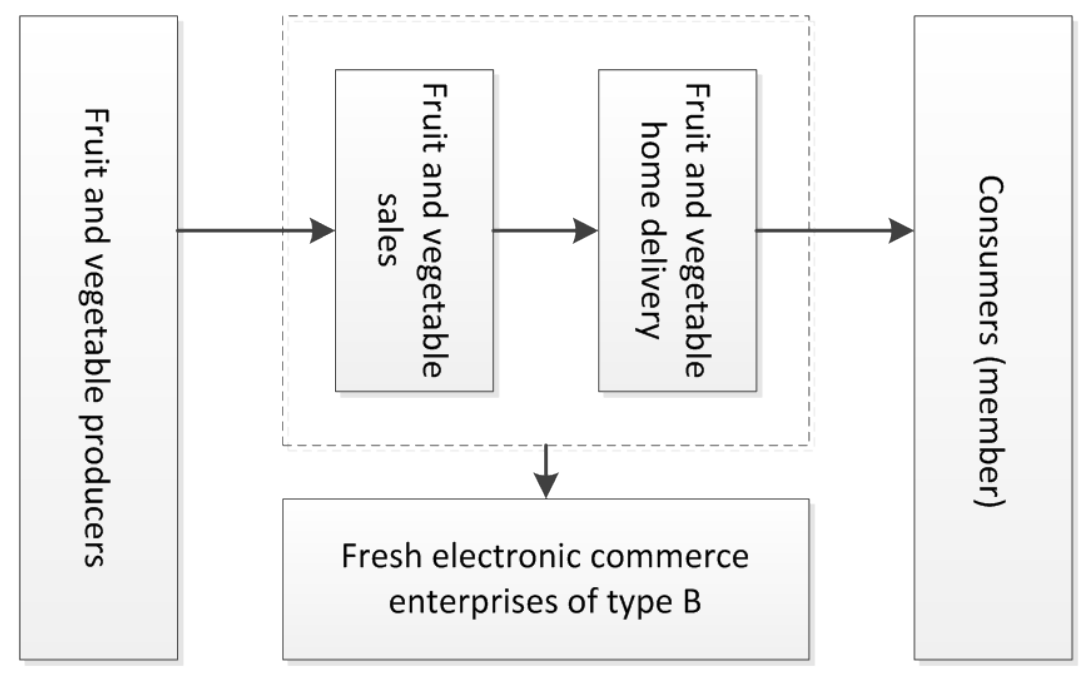

Figure 2. "Purchase + home delivery” mode operating diagram. 


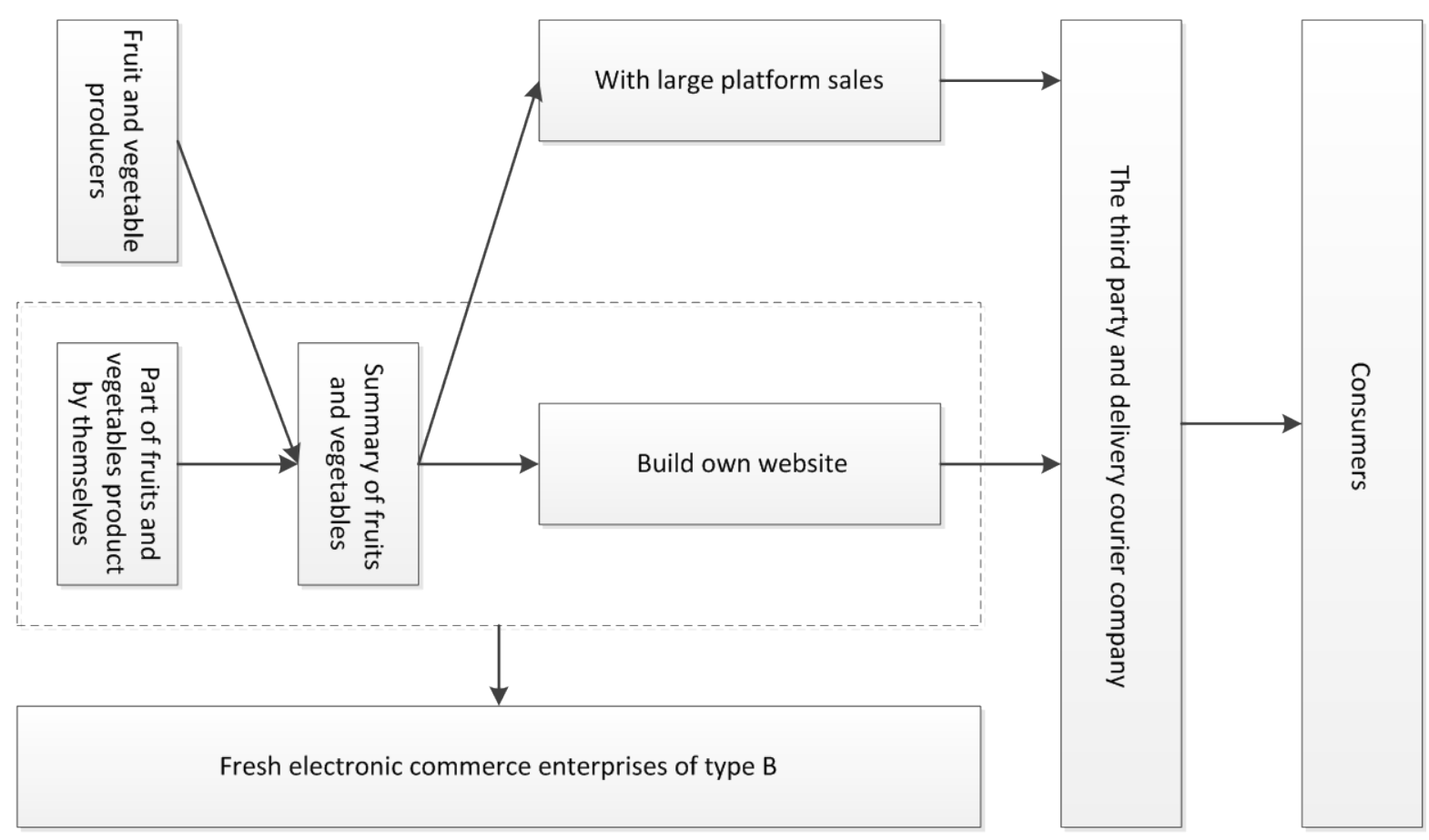

Figure 3. Relying on sales of electronic business platform model operating diagram.

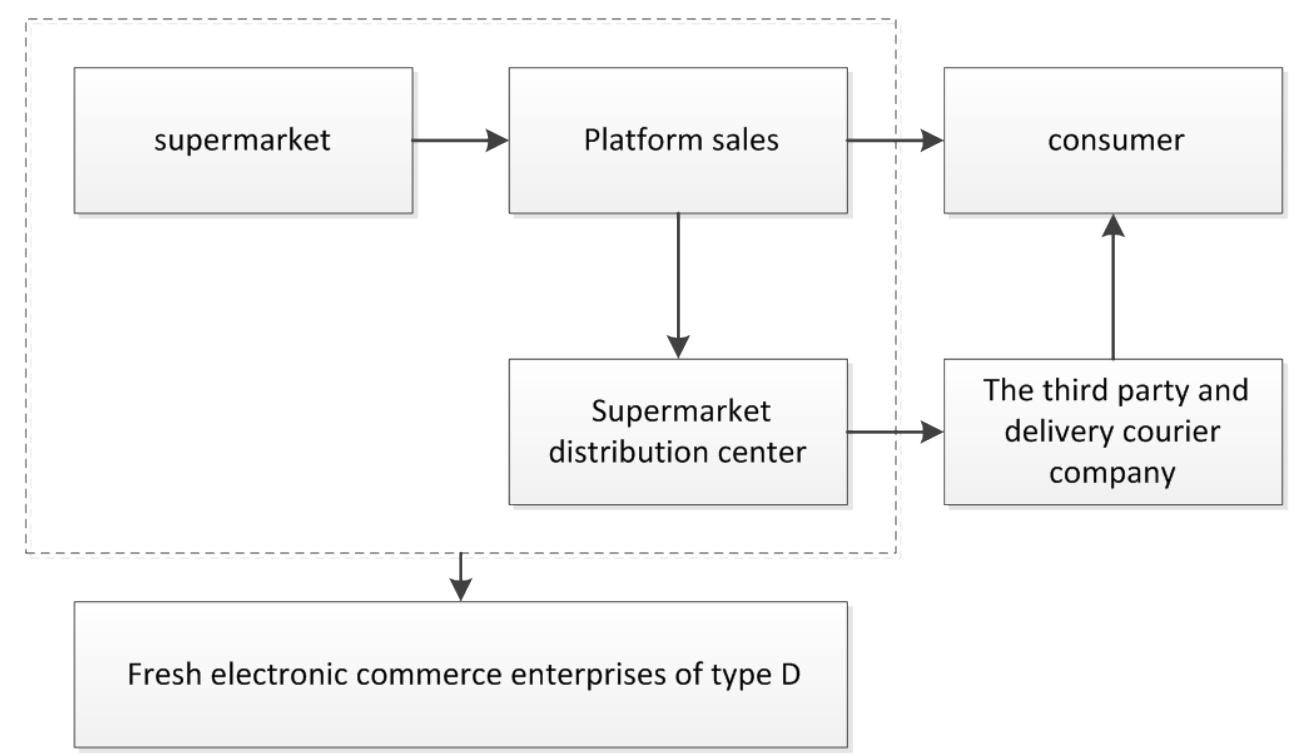

Figure 4. The expansion of traditional supermarkets to the e-commerce model operating diagram.

suppliers. So relying on the traditional supermarket delivery mode was born. Customers only need to log in their own familiar with the supermarket website. In the online choice to buy fruits and vegetables and other products, and then the distribution of the goods can be distributed at aappointed time.

The United States WAL-MART's samsclub and now a lot of Chinese local supermarkets have launched online shopping services. Online shopping Feiniu mall is from the traditional Darunfa supermarket extension. This model relies on the physical supermarket to increase the degree of trust of consumers. Each supermarket or supermarket distribution center can be regarded as a small transit center. Customer orders can be faster distribution after receiving their orders. 


\subsection{Fresh Fruits and Vegetables Last Mile Delivery Status}

Fresh electricity supplier select two ways deliver the fresh fruits and vegetables. First, fresh electricity supplier built logistics distribution system, through their own company's courier to the members of the product. In this way, the controllability of the product is stronger, can reduce the damage rate of fresh fruits and vegetables, can increase customer satisfaction. But the cost of built logistics distribution system is very high. The other is that the logistics outsourcing to the third party logistics company, the third party logistics company to complete the distribution. Select third party logistics companies can reduce the cost of electricity suppliers, electricity suppliers can focus on the development of core competitiveness. But with the third party logistics company, if the choice is not well, may be in the customer's last ring reduce customer satisfaction. Fresh fruits and vegetables last mile delivery, combined with the above mentioned two ways, become the following main modes: home delivery, community stores to join and intelligent express box.

1) Home delivery

This is the most common model, but also the distribution cost is highest. General use "Car + Courier", and delivery time negotiate with customers in advance. In our previous analysis of fresh electricity supplier development model "Own cultivated fields + home delivery" mode completely using this delivery mode. In several other modes of business, parts of them also use this model.

Home delivery model, generally suitable for the user is relatively concentrated business enterprise. If the electricity suppliers in a city have less customers, a large part of the time delay on the road, it is clear that do not match distribution efficiency type requirements.

2) Community stores to join

The community convenience store or a small grocery store is chosen as a fresh parcel from mentioning. Originally the store service model is single, customer groups fixed. To integrate these almost in each district are equipped with a small shop, equipped with an equipment of refrigeration. These shops will become a fresh delivery site. The courier put the area of customer orders into the community convenience store. Customers then go to the community to take their own fresh fruits and vegetables.

This model not only saves the distribution of the time, but also to facilitate customers to collect their own package. Convenience stores are generally located in a large flow of people, community residents to pass through the ground, as long as the customer takes their fresh fruits and vegetables by the way. However, the model of community stores could not be clearly judged responsibility when the problem appears. At last, the responsibility is often undertaken by fresh electricity suppliers.

The issue of the ability to trace the source is also relatively poor. Since the behavior increases to store staff flow of customers, at the peak of the pickup personnel may need to wait for a long time.

3) Intelligent express box

In recent years, in the large flow of people to install smart express from mentioning cabinet develop extremely quickly in China. Through the smart express cabinet installation has been in China one, second tier cities. But the special intelligent express from mentioning cabinet, for example, the heat preservation function, the cold storage function of the cabinet, but also mostly stay in the theoretical level. Three reasons can be given for this phenomenon: 1) High Cost. Domestic smart express cabinet equipment research and development, the installation cost price is about to maintain the 40 - 50 thousand per machine. Installation is also related to the venue rental, maintenance costs, electricity and other specific expenses, to promote the business in a wider range, or to solve the cost and other issues [7]. Needless to say with a specific function of intelligent delivery from mentioning cabinet. 2) Low utilization rate. Intelligent express from mentioning cabinet installed in the District, because it could not return, time constraints and other issues, leading to a lot of customers do not want to use intelligent courier cabinet. For time, temperature and other requirements of the fresh fruits and vegetables in the smart express cabinet storage utilization is very low. 3) Storage of goods outside the requirements are too standardized, express cabinet internal space is more standardized fixed cube space. This requires that the storage of goods outside the packaging must be standardized, and the volume could not be too large. Fresh fruits and vegetables in the process of distribution, different packaging, must be based on the shape of fruit and vegetable packaging, outside the shape of the package will undoubtedly limit the further development of intelligent express self.

\section{Analysis of Fresh Fruits and Vegetables Last Mile Delivery Problems}

Fresh fruits and vegetables last mile delivery and its direct contact is the distribution side and customer groups. 
We intend from the two aspects of analyzing the existing problems of the delivery of fresh fruits and vegetables.

\subsection{From the Distribution Side Analysis}

According to the China cold chain logistics alliance research data show that as of 2014 the total capacity of 20,469,713 tons of cold storage, cold storage vehicles only 29 thousand. In early 2010 launch of the national agricultural products cold chain planning, puts forward the goal of only to 2015 fruit and vegetable cold chain circulation rate of $20 \%$, refrigerated transport rate increased to $30 \%$. However, these data are still far below $90 \%$ in developed countries [8]. In fresh fruits and vegetables "last mile delivery, Beijing News reporter in 20157 - 8 month field survey of some fresh delivery courier companies in Beijing. The survey found that the so-called fresh delivery throughout the cold chain transportation, often into a "pseudo cold chain". In the last part of the delivery, the company generally distributes at room temperature by tricycle. This so called the whole process of cold chain transport, once the courier in the delivery of the delay, there is likely to lead fresh fruits and vegetables decay. There are some third party courier outlets did not add cold storage equipment. The fresh fruits and vegetables wrapped from the trunk line is placed at the distribution center at room temperature.

Some fresh self-supporting electric fresh fruit and vegetable delivery service, at the end of the distribution and community convenience store cooperation to fresh fruit and vegetables wrapped distribution to the community convenience stores, and then Then pick up by the clients. But some community convenience stores are not equipped with cold storage cabinets, fresh fruits and vegetables wrapped just casually placed in front of the door. This obviously accelerated the deterioration of fresh fruits and vegetables. Professional refrigeration equipment is very important in the process of fruit and vegetable delivery service, fresh electricity supplier in the self-support logistics and the third party cooperation must on the refrigeration equipment of strict inspection to ensure that the entire cold chain transport.

\subsection{From Customer Analysis}

1) The time limit for delivery of fresh fruit and vegetable preservation

At the end of the distribution of customer fresh business choose from mentioning the form. However, in the customer picked up in stores in lack of a kind of incentive mechanism let customers as early as possible pick up. Fresh parcels in the convenience store or the storage time is too long, it may lead to the deterioration of fresh fruits and vegetables. These deteriorating products are mostly paid by the fresh electricity suppliers, this result not only affect customer satisfaction, but also improve the operating costs of fresh electricity suppliers.

2) The distribution limits the development of fruit and vegetable delivery savings

Fresh fruits and vegetables "last mile delivery", although the existing distribution are varied, but the door to door delivery convenience will undoubtedly make customers more willing to choose the members of the distribution package sent directly to the hands of customers. However, the cost of this approach is the high cost of a large number of distributions.

\section{Some Proposals about Fresh Fruits and Vegetables Last Mile Delivery Development}

\subsection{Increase the Fresh End Equipment, and Achieve the Whole Process of Cold Chain Transport}

The fresh business self-support enterprises and engaged in fresh delivery courier company should as soon as possible to establish their own throughout the cold chain transport system. In the distribution center should be equipped with refrigerated cabinets, freezer cabinets, distribution vehicles equipped with refrigerated storage facilities. If part of the electricity supplier of fresh self-support system because of funding problems could not operate, the company should decisively abandoned, focus on their own core competitiveness, the fresh delivery module outsourcing to specialized in fresh delivery logistics enterprises for distribution. For cooperation from the community to join the community, the integration of enterprises must be strictly, to ensure that every community stores are in line with the standards of fresh storage.

\subsection{Select a Reasonable Place to Install Advanced Equipment}

Some enterprises related to the introduction of advanced equipment fresh delivery must fully consider the cha- 
racteristics of the choice. Such as intelligent refrigeration express cabinet installation, if the installation of such a courier cabinet in each district costs naturally high, and the use of this kind of express cabinet is also relatively low. If you put this freezer express cabinets installed into a large flow of people, as long as the location of the customer by the way to take away their own fresh parcels. This method can not only improve the utilization of equipment, but also can be convenient for customers. For example, in Shanghai, Beijing and other large cities in the distribution of large distribution of large cities, in the subway station to install such a courier. In the subway, customers can conveniently take away their own purchase of fresh fruits and vegetables.

\subsection{The Government Introduced the Relevant Support Policies as Soon as Possible}

Fresh electronic business is known as the last piece of blue oceans, attracting a large number of entrepreneurs and investors to come to the nuggets. However, entrepreneurs and investors invest in this piece of the oceans, only to find that the situation is not so optimistic. China has a vast territory, although the construction of the network platform has reached a point of perfection, the supporting hardware facilities could not keep up with the pace of development. Especially at the end of the last delivery, the government should introduce a number of specific measures to support the needs of rapid development. For example, the problem of refrigerated trucks trafficin the city, the problem of electricity suppliers to sell fruits and vegetables to identify the fresh degree. Only the government as soon as possible to support some fresh delivery policies can ensure the rapid development of China.

\section{Conclusions}

With the improvement of people's living standard and the convenience of the consumer psychology, people pay more attention to the health of the diet. Fresh electricity enterprises will be in full swing in the future development. Fresh delivery also keeps pace with the development of the matter; home delivery should do a good job of connecting between fresh electricity providers and consumers. The last mile delivery is the last part of the distribution of direct contact with consumers. The entire transaction process is essential. Enterprises must pay attention to this process.

Chinese fresh delivery is still in the initial stage of development. Although this article refers to a large number of literature, the survey data and information is limited because of the present situation; the analysis of "the last kilometer" delivery is not enough thorough and the suggestion is partial. Hope in the future the research can be further deepened.

\section{References}

[1] Li, J.R. (2010) Research Progress of Fresh Food Preservation Technology. China Journal of Food Science, 3, 1-12.

[2] Li, Z. and He, X.Y. (2009) Research on the Construction of Fruit and Vegetable Logistics Process. China Circulation Economy, 23, 29-31.

[3] Gong, T.F., Zhang, L. and Bi, J.P. (2014) Domestic and Foreign Fresh Electricity Suppliers Operating Mode Analysis and Revelation. Shopping Modernization, 27, 27-30.

[4] Cheng, Y.H. (2014) Study on the Fresh Electronic Business Model in the United States. World Agriculture, 8, 76-79.

[5] Zhong, Z. (2015) Observation of Our Agricultural Products e-Commerce Research and Development Status of Cold Chain Delivery. Management, 4, 84-87.

[6] Jin, W.W. (2015) Analysis of Fresh Business Brand Marketing Strategy—To "Dolly Farm” for the Journal of Cases. Nanjing Institute of the Arts (Art and Design Edition), 3, 192-196.

[7] Wang, J.Q. and Zou, E. (2015) Online Shopping Terminal Logistics Application Smart Courier Cabinet Mode Analysis of. Logistics Technology, 5, 58-60.

[8] Li, D. (2015) Cold Chain Is Not “Cold” Fresh Distribution Defeat in the Last Mile. Chinese Food, 14, 108-109. 


\section{Submit or recommend next manuscript to SCIRP and we will provide best service for you:}

Accepting pre-submission inquiries through Email, Facebook, LinkedIn, Twitter, etc.

A wide selection of journals (inclusive of 9 subjects, more than 200 journals)

Providing 24-hour high-quality service

User-friendly online submission system

Fair and swift peer-review system

Efficient typesetting and proofreading procedure

Display of the result of downloads and visits, as well as the number of cited articles

Maximum dissemination of your research work

Submit your manuscript at: http://papersubmission.scirp.org/ 